Sharif University of Technology
Scientia Iranica
SCIENTIA
I RAN I CA
http://scientiairanica.sharif.edu

\title{
Evaluation of peak ground acceleration for the city of Kerman through seismic hazard analysis
}

\author{
M. Saafizaadeh ${ }^{\mathrm{a}}$ and M.H. Bagheripour ${ }^{\mathrm{b}, *}$ \\ a. Department of Geophysics, University of Advanced Technology, Kerman, Iran. \\ b. Department of Civil Engineering, Faculty of Engineering, Shahid Bahonar University of Kerman, Kerman, Iran. \\ Received 25 April 2017; received in revised form 1 July 2017; accepted 31 July 2017
}

\author{
KEYWORDS \\ Seismic hazard \\ assessment; \\ PGA; \\ Kerman; \\ Earthquake hazard \\ parameters; \\ CRISIS2007; \\ Kijko method.
}

\begin{abstract}
In this paper, Probabilistic Seismic Hazard Analysis (PSHA) approach is used to evaluate the distribution of Peak Ground Acceleration (PGA) and its corresponding probabilities for Kerman region in S-E of Iran. The geological and seismological data are integrated into a probabilistic seismic hazard model for the region. Historical and instrumental earthquake data, geology, tectonics, fault activity, and seismic source models associated with seismic events are taken into account. Foreshocks and aftershocks are rationally eliminated, and main shock records are used to evaluate seismicity parameters using Kijko method. The use of such a method is advantageous since it accounts for incomplete or inaccurate seismic data related to various seismic sources in the region. CRISIS2007 software is also used to carry out seismic hazard analysis for the region and to develop the maps of iso-acceleration contours for various return periods. The results have been displayed as the probabilistic estimates of PGA for the return periods of 50, 75, and 475 years. Comparing the results obtained here with those suggested by the Iranian Code of Practice for Seismic-Resistant Design of Buildings (Standard No. 2800 Version 1393) is also carried out. Results obtained in this study provide the basis for the preparation of seismic risk maps.

(C) 2019 Sharif University of Technology. All rights reserved.
\end{abstract}

\section{Introduction}

Iran is located in one of the most seismically active zones in the world, which is situated over the AlpHimalayan seismic belt. Many historical and strong earthquakes occurred in Iran during the past centuries, causing significant damages and loss of lives. The southern east of Iran, in particular, is a potential area susceptible to strong earthquakes in which Kerman region is the subject of the current investigation. The historical strong earthquakes of Bam occurred

\footnotetext{
*. Corresponding author.

E-mail addresses: maalek.saafizaadeh@gmail.com ( $M$. Saafizaadeh); bagheri@uk.ac.ir (M.H. Bagheripour)
}

doi: $10.24200 /$ sci. 2017.4236 in December 2003 led to the total loss of more than 26000 lives; such a disaster is a notable event in Kerman's regional seismic history. Seismotectonic, fault rupture process and rupture mechanism, distribution and spread patterns of aftershocks, failure through coseismic or postseismic stress loading as well as earthquake hazard aspects of the 2003, December 26 Bam earthquake (Iran), 6.6 MW, have been investigated by many investigators, including Tatar et al. (2005), Jackson et al. (2006), and Nalbant et al. (2006) [1-3].

In a study on the field and teleseismic observations of the 1981 Golbaf-Sirch earthquakes in S-E Iran, Berberian et al. (1984) concluded that the considered surface faulting in two earthquakes was complex and spread over the width of several kilometers [4].

Berberian et al. (2001) also studied the 1998 March 14 Fandoqa earthquake (6.6 MW) in Kerman 
province, re-rupture of 1981 Sirch fault triggering slip on adjacent thrusts, and the active tectonics of the Gowk fault zone [5].

Talebian et al. (2006) investigated the Dahuiyeh (situated in Zarand of Kerman province) earthquake of 2005, February 22 in central Iran and the reactivation of an intermountain reverse fault striking E-W and dipping north at $60^{\circ}$ to the depth of about $10 \mathrm{~km}$. A clear, mapped surface rupture was produced to study with InSAR that further represented a serious seismic hazard in Iran, which was too difficult to assess [6].

Rouhollahi et al. (2012) investigated the source process and slip model of 2005 Dahuiyeh-Zarand earthquake (Kerman, Iran) using inversion of near-field strong motion data. They found that the final fault slip model and the estimated source parameters were able to explain the observed waveforms [7].

From geological point of view, Kerman city is located on a relatively high plain of $1740 \mathrm{~m}$ above the sea level and is surrounded by Joupar mountain in its south [8]. Moreover, site geotechnical investigations and, especially, subsurface explorations have shown that most of surface soils in and around the city are of relatively deep deposits of fine-grained materials. Such geological formations are known to have significant seismic site effects and, especially, resonance and amplitude amplification characteristics.

Based on the investigations summarized in the preceding paragraphs and on the occurrence of many other earthquakes in the area during recent years, it can be inferred that these faults have been activated; hence, Kerman region should be the subject of further investigations. To better design seismic-resistant structures and, even, retrofit the existing buildings against future seismic events in the region, it is necessary to estimate the likelihood of various levels of earthquake ground motions at a given location in the region and in an assumed future time period. Probabilistic Seismic Hazard Analysis (PSHA) approach is used usually to carry out such estimations.

In this paper, PSHA approach is used to evaluate the distribution of Peak Ground Acceleration (PGA) and its corresponding probabilities for Kerman region in S-E of Iran. The geological and seismological data have been integrated into a probabilistic seismic hazard model for that region spanning the area between $30^{\circ} 14^{\prime}-30^{\circ} 19^{\prime} \mathrm{E}$ and $57^{\circ} 0^{\prime}-57^{\circ} 7^{\prime} \mathrm{N}$. A database that includes a seismic catalogue of both historical and instrumental earthquake records occurred in the 20th century up until to 2014 has been established. It covers information on seismotectonic system and coordinate information related to regional faults. The database is filtered for foreshocks and aftershocks, and mainshock records are maintained. Based on the regional seismotectonics and fault map as well as on the distribution of earthquake, seismic sources are defined and typified before being attributed to some of these regional and relevant earthquakes.

Kijko method (1989-2000), based on GutenbergRichter (1956) double truncated distribution function, was used to evaluate seismicity parameters of the sources defined in the course of investigation. The use of such a method is advantageous since it accounts for incomplete or inaccurate seismic data related to various seismic sources in the region. CRISIS2007 software is also used in the current study to carry out seismic hazard analysis for the region and develop the maps of iso-acceleration contours for various return periods. CRISIS2007 is a powerful software due to its interesting embedded library of information from previously recorded seismic events, which can be used for the region under study [9-11].

Adopted return periods include 50, 75, and 475 years for which PGA values are evaluated as $0.17 \mathrm{~g}, 0.23 \mathrm{~g}$, and $0.6 \mathrm{~g}$, respectively, in the analysis. The Iranian Code of Practice for Seismic-Resistant Design of Building (Standard No. 2800 Version 4) [12] also suggests PGA values for the region and for design- and performance-based earthquakes corresponding to 475 years of return periods, respectively. Therefore, results obtained here are compared with those suggested by this code of practice.

In the following sections, details of the PSHA approach used to carry out seismic hazard analysis and evaluate the seismicity parameters are described.

\section{Earthquake database}

A review of Iran's historical earthquakes (pre-1900) is provided by Ambraseys and Melville (1982) [13]. To improve the quality and accuracy of these earthquake data, the new Earthquake Catalogue of Iran was compiled by Berberian in 1994 [14]. For the present century, the IIEES catalogue based on reports from International Seismological Centre (ISC) has been used [14].

Since mid-1960 s, the installation of seismograph, founding of stations, and the development of global, regional, or local seismological networks have facilitated recording seismic events and rather accurate locating with earthquakes' focal mechanism. A reliable earthquake database for Iran existing for the last few decades has been considered. Both of the catalogues mentioned above have provided a base for the spatial correlation of the seismicity with the seismotectonic sources in Iran [15].

From 1930 to 1985, the seismicity analysis of Iran was conducted by Niazi and Basford (1968), Nowroozi (1971, 1976), Banisadr (1971), Ambraseys and Moinfar (1973), Berberian (1973), and Tchalenko (1975) [1622]. In addition, Nabavi (1978), Berberian (1979), and Ambraseys et al. (2005) [23-25] all made tremendous efforts to collect and edit seismic data related to Iran. 
Among all Iran's historical earthquake records, the collected set by Ambraseys et al. (2005) appears to have higher consistency, when compared with those given by other investigators [25].

Several investigators now concur that the seismicity in Iran is related to the local surface geology and tectonics. Many destructive earthquakes in the last century listed in Table 1 confirm this phenomenon.

The Iranian plateau is one of the seismically active areas of the world and, frequently, suffers from destructive and catastrophic earthquakes that cause heavy loss of human life and widespread damage. Figure 1 maps the recent seismicity of Iran, showing the high inhomogeneity and dispersion of the seismic activity in the Iranian plateau. In the current study, both historical and instrumental earthquake data have been selected within the radius of $150 \mathrm{~km}$ around Kerman city (Figure 2).

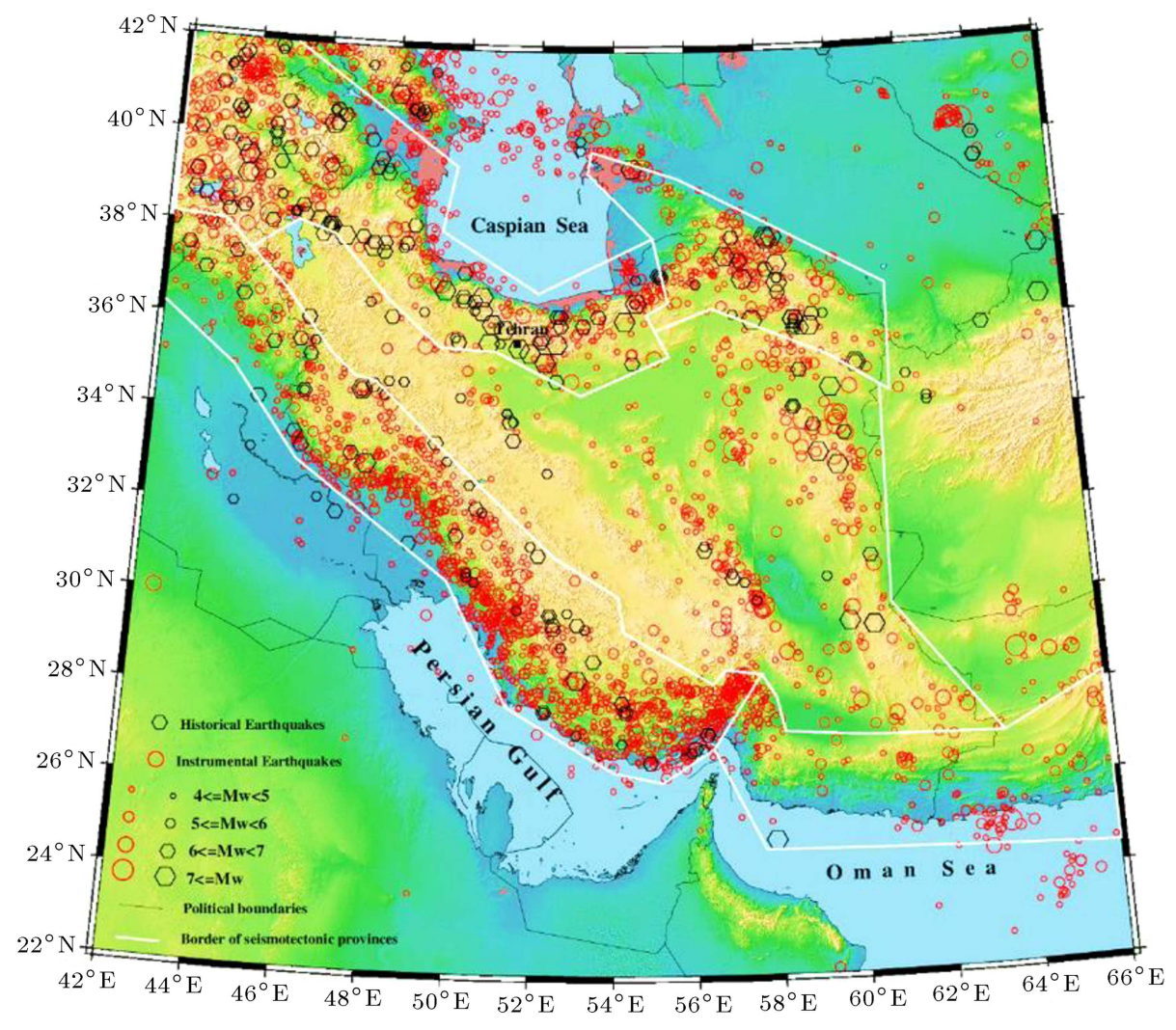

Figure 1. Recent seismicity of Iran [26].

Table 1. Recent destructive earthquakes in Iran [15].

\begin{tabular}{ccccc}
\hline No. & Year & Location & Damage & Magnitude \\
\hline 1 & 1909 & Silakhur & 8000 dead, 64 villages destroyed. & 7.4 \\
2 & 1930 & Salmas & 2514 dead, 60 villages destroyed. & 7.4 \\
3 & 1953 & Torud & 183 dead, 200 villages destroyed. & 6.4 \\
4 & 1960 & Lar & 400 dead, 75\% Lar destroyed. & 6.7 \\
5 & 1962 & Buin Zahra & 10000 dead, destructive damage. & 7.2 \\
6 & 1968 & Dshte-e-bayaz & 10500 dead, 61 villages destroyed. & 7.4 \\
7 & 1972 & Qir & 4000 dead, a lot of damage. & 6.9 \\
8 & 1977 & Khurgu & 128 dead, very economical damage. & 7.0 \\
9 & 1978 & Tabas & 19600 dead, 16 villages destroyed. & 7.7 \\
10 & 1979 & Qayen & 130 dead, 150 villages destroyed. & 7.1 \\
11 & 1990 & Rudbar Manjil & 35000 dead, some cities and villages destroyed. & 7.2 \\
12 & 1997 & Birjand & Over 1500 dead. & 7.3 \\
13 & 2003 & Bam & 26271 dead, 30000 injury. & 6.6 \\
\hline
\end{tabular}




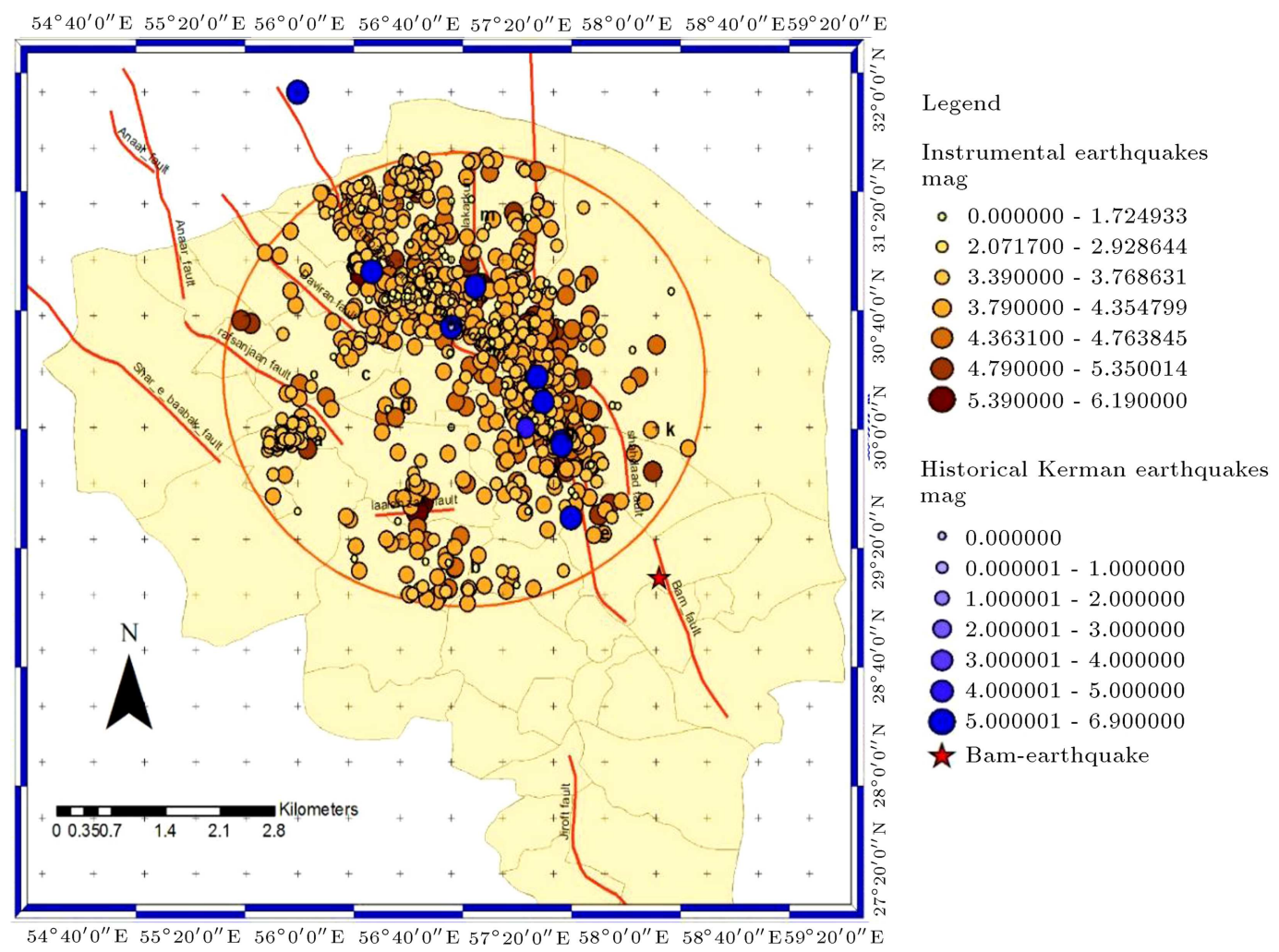

Figure 2. Historical and instrumental earthquake map of Kerman region.

\section{Seismotectonics of Kerman}

The Iranian plateau can be characterized by active faults, recent volcanoes, and relatively high surface elevation along the Alpine earthquake belt. Tectonic studies have demonstrated that the Iranian plateau has very high density of active and recent faults. Earthquake data show that most activities are concentrated along the Zagros fold thrust belt, while relatively fewer activities are observed in Central and Eastern parts of Iran. Nevertheless, strong earthquakes in the southern east of Iran are not few, and the earthquakes mentioned in the preceding paragraphs are emphatic in this issue. Therefore, several regions remain vulnerable to destructive earthquakes, including Kerman region, requiring further seismic investigations [27].

Preparation of an earthquake hazard map requires the delineation of the seismotectonic province and the assessment of the associated maximum earthquake potentials. They can be defined as a geographic region of some geological, geophysical, and seismological similarities with the assumption of uniform earthquake potential. Earthquakes are assumed to occur randomly throughout the seismotectonic provinces, even though the earthquake record may indicate some clustering at preferred locations. The seismotectonic provinces of Iran are then defined as areas bounded by geological features that mark a difference in seismic characteristics of one province from its neighboring provinces.
Each province has equal seismic potential and uniform geological structures and trends.

Several investigators studied the structure of Iran in the past. Stocklin (1968), Takin (1972), and Berberian (1976) suggested simplified divisions consisting of only nine, four, and four regions, respectively [28-30]. A more elaborated division, consisting of twenty-three seismotectonic provinces, was suggested by Nowroozi (1976) [18]. A new model of seismotectonic provinces was also proposed by Tavakoli (1996) [31].

The boundaries of the provinces were established through analysis of seismic history, relocated epicenter for the past several decades, tectonic environments, active faults, regional geomorphology, and plate boundaries. Tavakoli (1996) divided Iran into 20 seismotectonic provinces, shown in Figure 3 [31]. The known active faults of Iran are located within these twenty seismotectonic provinces.

In general, Kerman province is located in a special seismotectonic condition that includes different relative seismic hazard levels [6]. Kerman city, in particular, is situated in the vicinity of some major faults among which Kuhbanan, Chatroud, Nayband, Lakarkuh, and Golbaft-Sirch faults can be named. Numerous and other faults exist and have been recognized in Kerman province that can be added to the list. However, it will lead to a lengthy discussion, which is beyond the scope of this paper.

Table 2 shows characteristics of faults introduced 


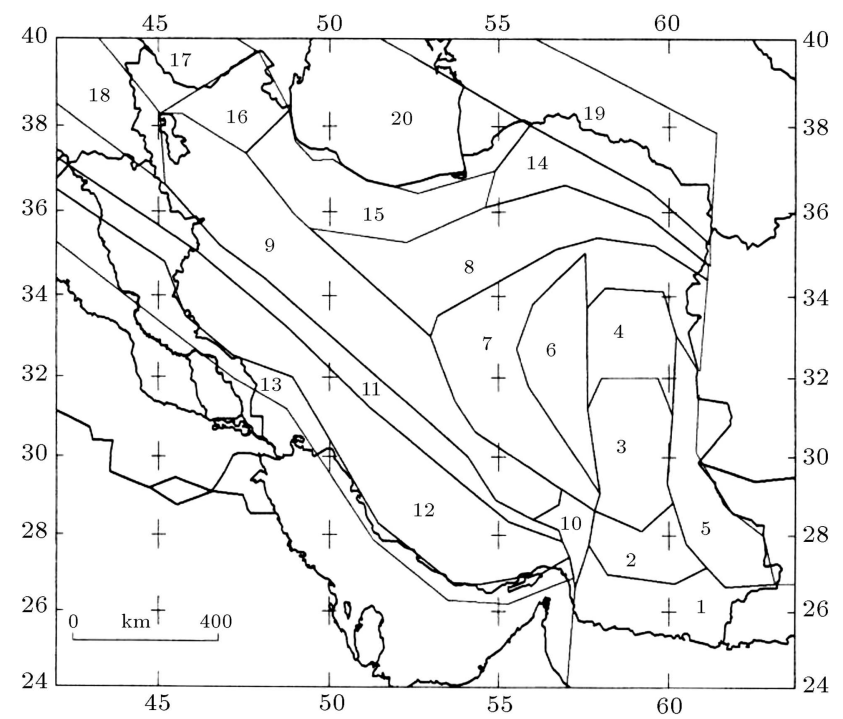

Figure 3. Seismotectonic provinces of Iran [31].

Table 2. Active faults of Kerman province.

\begin{tabular}{cccc}
\hline No. & $\begin{array}{c}\text { Fault } \\
\text { name }\end{array}$ & $\begin{array}{c}\text { Type of } \\
\text { faulting }\end{array}$ & $\begin{array}{c}\text { Length } \\
(\mathbf{k m})\end{array}$ \\
\hline 1 & Kuhbanan fault & Strike slip & 900 \\
2 & Jiroft fault & Strike slip & 90 \\
3 & Golbaaf-Sirch fault & Strike slip & 60 \\
4 & Gowk fault & Strike slip & 100 \\
5 & Lakarkuh fault & Strike slip & 130 \\
6 & Nayband fault & Strike slip & 600 \\
7 & Rafsanjaan fault & Strike slip & 160 \\
8 & Laaleh zaar fault & Thrust fault & 50 \\
9 & Shahdaad fault & Thrust fault & 120 \\
10 & Bam fault & Strike slip & 65 \\
\hline
\end{tabular}

in Kerman province. Figure 4 also depicts locations of active faults in this province. The existence of active faults as well as the occurrence of severe earthquakes in Kerman province are all indications of high seismic potential and probability of future strong earthquakes. Therefore, seismic hazard analysis for Kerman city appears to be of prime importance.

\section{Earthquake magnitude}

Generally, to carry out seismic hazard analysis, $M_{w}$, $M_{b}$ or $M_{L}$ is used as a magnitude scale. In the current study, standardization of the catalogue in terms of the magnitude was achieved by the conversion of all types of magnitude (in the catalogue) into moment magnitude, $M_{w}$. The moment magnitude has a strong physical meaning and, as defined by Hanks and Kanamori (1979) [32], is related to the total amount of energy released during an earthquake which is, in turn, rationally related to seismic moment, $M_{0}$ [33]. $M_{0}$ is

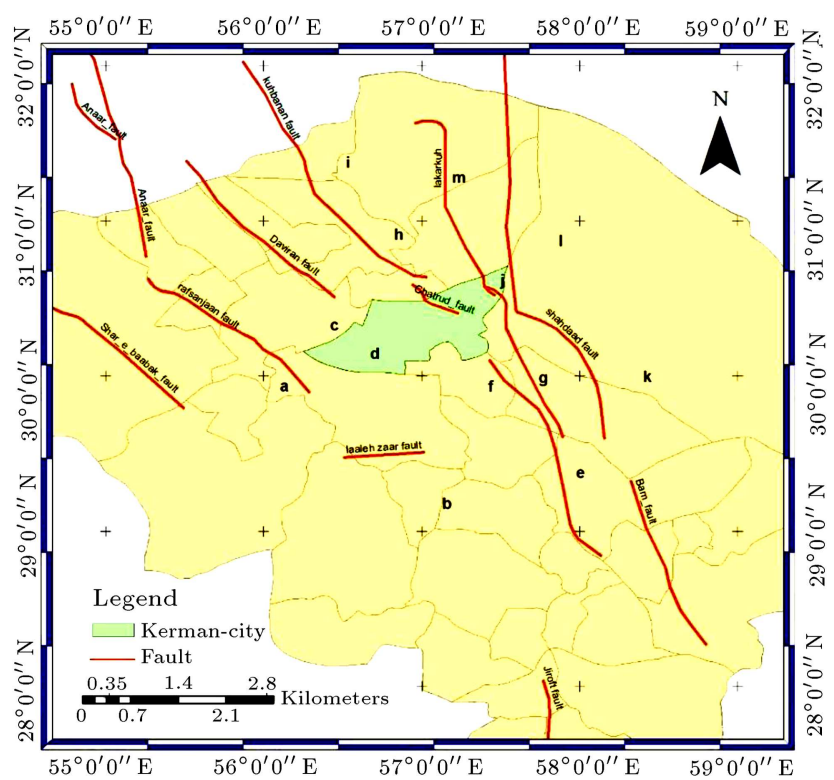

Figure 4. Active faults in Kerman province.

the most fundamental physical parameter of a seismic source that expresses the size of an earthquake. Most of the widely used ground-motion prediction equations use $M_{w}$ magnitude as a prime scaling parameter.

In this study, to develop uniform moment magnitude data, $M_{w}$ was chosen as the base of calculation and scaling process. Linear relationships were used for $M_{b}, M_{S}, M_{L}$, and $M_{N}$ versus $M_{w}$ magnitude [34].

The method introduced in reference [34] was used for conversion of magnitudes, and all other magnitude scales were converted to $M_{w}$. The reason for this conventional conversion is that $M_{S}$ and $M_{b}$ magnitudes scales are virtually saturated at large magnitudes and they lose their efficiency and applicability. The $M_{w}$ magnitude scale may not saturate as might occur for $M_{S}$ or $M_{b}$ and appears to be a more suitable scale. Such conversion may slightly reduce the accuracy of the method; however, the extension of such a reduction depends strongly on the adopted relation. If the appropriate relation is adopted, similar to what was carried out in this research, minimum reduction is expected to affect the results. In order to follow the conversion process appropriately, all other magnitude data are grouped into $M_{S}, M_{b}$, and $M_{L}$. Then, they are converted to $M_{w}$ based upon the flowchart shown in Figure 5.

In summary, a two-step procedure is adopted such that, for example, $M_{L}$ values are converted into $M_{N}$ and, then, into $M_{w}$ values, successively. The general procedure for all conversions is summarized and schematically shown in Figure 5. The figure includes the linear equations used for conversions. Having converted all magnitude types into $M_{w}$, all earthquakes with $M_{w}<3.5$ are removed from the newly compiled earthquake data. 


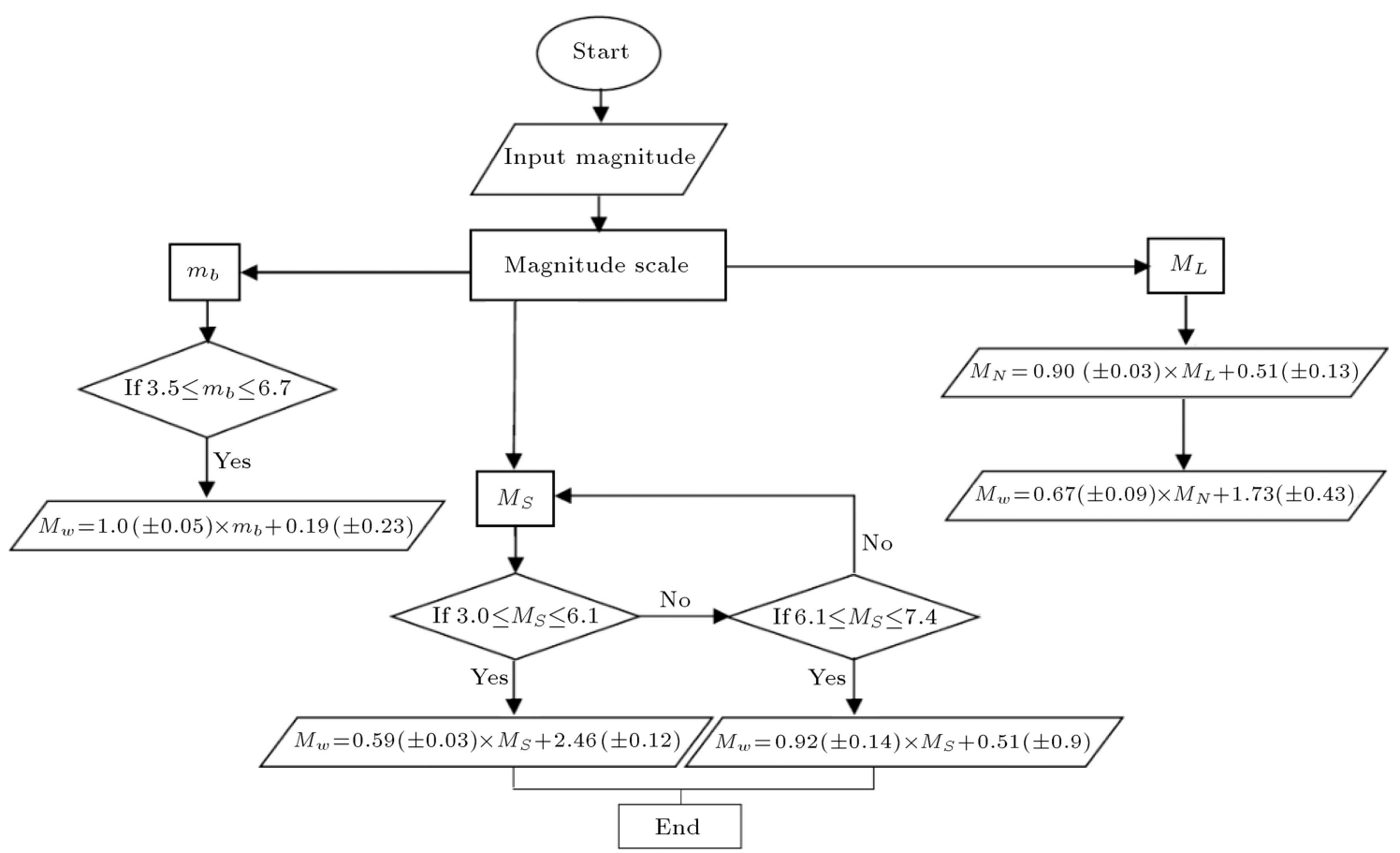

Figure 5. Procedure developed in this study to convert all magnitude to $M_{w}$.

\section{Earthquake hazard parameters}

Earthquake hazard analysis requires the assessment of earthquake hazard parameters. In this section, these parameters are evaluated for each seismic source around Kerman city. Since earthquake magnitude is mostly reported with some uncertainties in Iran, the maximum likelihood estimation for definition of the earthquake hazard parameter is of prime concern $[35,36]$. As will be discussed in the following paragraphs, the maximum likelihood method is applied, allowing the combination of both historical and instrumental data [9-11,37].

\subsection{Magnitude recurrence laws}

Magnitude recurrence law (or relation) allows the seismic hazard analyst to take the uncertainty of earthquake size into account and to further define the distribution of earthquake sizes (mostly magnitudes) in a given period of time [38]. Such relations, in fact, predict future seismic activities in a region based on past activities. Two types of model may be used to express magnitude distribution of a variety of earthquake sizes in a region: Gutenberg-Richter and characteristic earthquake models (e.g., [39-41]).

Kijko and Sellevoll (1989) introduced an interesting method for seismic hazard parameter determination which was, in fact, an extension of the general procedure for maximum likelihood estimation of earthquake hazard parameter including maximum regional magnitude, $M_{\max }$, seismic activity rate, $\lambda$, and GutenbergRichter (1956) recurrence law parameter, $b$ [39]. The extended procedure introduced by Kijko and Sellevoll (1989) considers the case of having combined data including information registered in the macroseismic (large historic seismic events) section of the seismic catalogue and those related to recent seismic events defined in the catalogue [9]. In an attempt to improve their original method with the deficiency of not properly handling the magnitude uncertainties, Kijko and Sellevoll (1992) observed that earthquake magnitudes were never exactly known, since the information related to historical events, due to the lack of suitable documentation as well as misunderstanding in damage evaluation and description, might have created considerable uncertainties, which all contribute to overall uncertainties [10]. Kijko and Sellevoll (1992) also described the uncertainties in even instrumentally determined magnitude values [10]. They noted that the conversion of various types of magnitudes into a single or common measure requires empirical conversion relations to be used for the whole span of the catalogue. They made reference to the previous studies carried out by other investigators who suggested the invalidity of such a procedure [10]. A more comprehensive approach, therefore, was introduced by Kijko and Sellevoll (1992) to handle magnitude determination appropriately when the dataset is heterogeneous [10].

A parametric-historic procedure for probabilistic seismic hazard analysis was discussed also by Kijko and Sellevoll (1992) [10]. They proposed that the historical part of the seismic catalogue included only the strongest seismic events, whereas the complete part could be further subdivided into several minor 
catalogues; each of these catalogues assume a specified threshold of magnitude partially while uncertainties in magnitudes are also properly taken into account. The original approach was further developed and extended by Kijko and Graham (1999), particularly to conduct seismic hazard evaluation at individual sites regardless of the judgments subjectively involved in the definition of seismic source zones, where specific active faults have not been mapped and identified and when the cause of seismicity is not well understood [37].

More recently, a computer program was developed by Kijko (2000) that incorporates all aspects of the seismic hazard parameter determination approach described in preceding paragraphs [11]. In summary, computer program of Kijko (2000) utilizes the maximum likelihood estimation probabilistic approach using the extreme distribution function for historical seismic records with low accuracy and large magnitude as well as the double truncated GutenbergRichter distribution function for instrumental earthquake records. Based on the study conducted in the current research and also in other studies as well as on the efficiency of the Kijko's (1989-2000) method, this computer program was used in this paper to conduct seismic hazard analysis in Kerman city. The use of Kijko's (2000) computer program is further justified in this study, primarily because earthquake magnitudes are mostly reported with some uncertainties in Iran; hence, the maximum likelihood estimation approach to earthquake hazard parameter determination becomes of prime concern [11].

The analytical method introduced by Kijko was, in fact, extended, modified, and integrated into a mathematical and statistical software. The software is a user-friendly computer program that inhibits all relations considered in Kijko method at its internal library. For the user of the Kijko's computer program, it is only necessary to input the data related to seismic catalogue and use the software to output the seismicity parameter of the region under study.

In order to easily attribute all existing earthquakes in the region to the appropriate seismic sources, an attempt is made to consider most of the seismic sources as planar source. This is because the distribution of earthquakes over the regional faults is disperse.

Figure 6 presents seismic sources that have been recognized and defined by authors for Kerman city. In this case, records of earthquakes occurring in the twentieth century up until year 2014 are used to evaluate earthquake hazard parameters. The earthquake hazard parameters estimated for each earthquake source of Kerman city are shown in Table 3 .

In Table $3, M_{\max }, \lambda$, and $\beta=\ln b$ are the $\max -$ imum magnitude, the number of earthquakes having magnitudes larger than $M_{\max }$, and the constant of Gutenberg-Richter relation, respectively.

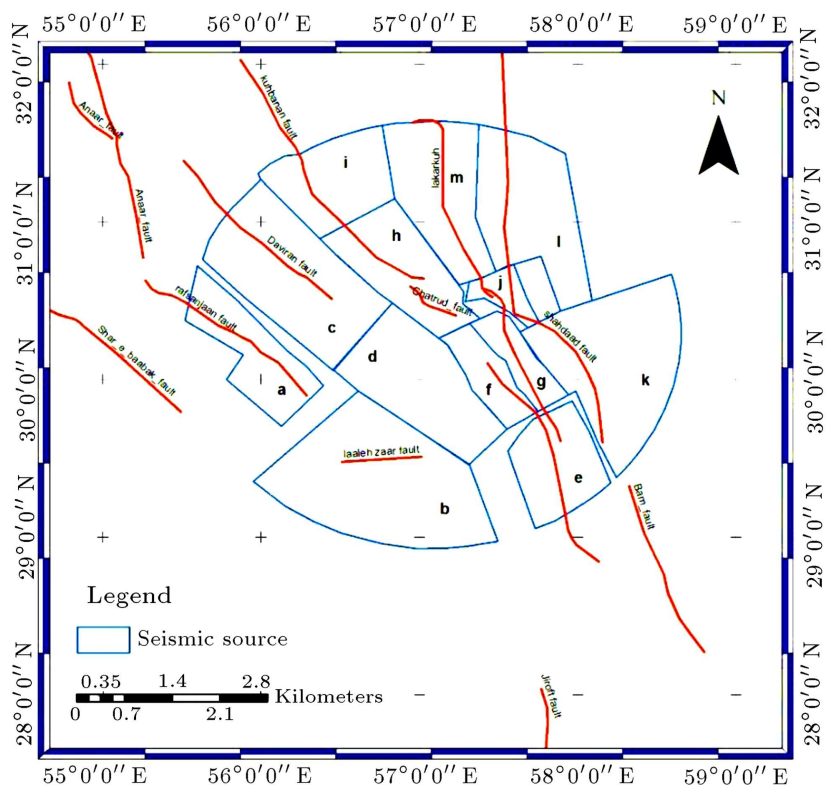

Figure 6. Seismic sources according to seismicity map of this region.

\section{Predictive relationships}

Predictive (attenuation) relationship commonly defines ground motion parameters as a function of magnitudes, distance, and in some cases in terms of other variables such as source features, fault slip mechanism, site's geological (soil or rock layers) and topographical conditions, wave path, as well as tectonic regime. In summary, the relations express how quickly ground motions decrease as the distance from a seismic event increases. These relationships are usually developed by regression analysis of recorded strong motion in the seismic catalogues. Hence, such regressed relationships may be changed or updated with time, since the additional information may become available [38]. As discussed by Kramer (1996), changes may be seen every 3 to 5 years or shortly after the occurrence of large seismic events in well-instrumented regions [38].

Despite the fact that many such relations have been introduced in the literature, they can be simplified into some simple and general mathematical equations; the general form of the attenuation relation may be considered as follows:

$$
\log (a)=f_{1}(M)+f_{2}(r, E)+f_{3}(r, M, E)+f_{4}(F)+\varepsilon,
$$

where $a$ is the peak ground acceleration (horizontal or vertical), $f_{1}(M)$ is a function of earthquake magnitude, $f_{2}(r, E)$ is a function of earthquake-to-recording site distance and the tectonic environment, $f_{3}(r, M, E)$ is a non-separable function of magnitude, distance and tectonic environment, $f_{4}(F)$ is a function of fault type, and $\varepsilon$ is a random variable representing uncertainty in $\log (a)$ [42]. 
Table 3. Seismicity parameters of each seismic source in the study area.

\begin{tabular}{cccccc}
\hline $\begin{array}{c}\text { Seismic source } \\
\text { name }\end{array}$ & $\boldsymbol{\beta}$ & $\boldsymbol{b}$ & $\boldsymbol{\lambda}$ & $\boldsymbol{M}_{\max }$ & $\begin{array}{c}\text { Seismic source } \\
\text { type }\end{array}$ \\
\hline $\mathrm{a}$ & $2.41 \pm 0.16$ & $1.05 \pm 0.07$ & $1.2 \pm 0.33$ & $5.3 \pm 0.5$ & Planar \\
$\mathrm{b}$ & $1.48 \pm 0.14$ & $0.64 \pm 0.06$ & $2.04 \pm 0.34$ & $6.1 \pm 0.5$ & Planar \\
$\mathrm{c}$ & $2.3 \pm 0.16$ & $1 \pm 0.07$ & $1 \pm 0.33$ & $5 \pm 0.5$ & Linear \\
$\mathrm{d}$ & $2.25 \pm 0.16$ & $0.97 \pm 0.07$ & $0.95 \pm 0.32$ & $5.1 \pm 0.5$ & Planar \\
$\mathrm{e}$ & $2.21 \pm 0.15$ & $0.96 \pm 0.07$ & $1.36 \pm 0.3$ & $5.8 \pm 0.5$ & Planar \\
$\mathrm{f}$ & $2.03 \pm 0.16$ & $0.88 \pm 0.07$ & $0.57 \pm 0.15$ & $5.9 \pm 0.5$ & Planar \\
$\mathrm{g}$ & $1.34 \pm 0.13$ & $0.58 \pm 0.06$ & $1.21 \pm 0.18$ & $6.7 \pm 0.5$ & Planar \\
$\mathrm{h}$ & $1.65 \pm 0.14$ & $0.72 \pm 0.06$ & $1.07 \pm 0.18$ & $6.6 \pm 0.5$ & Planar \\
$\mathrm{i}$ & $2.12 \pm 0.15$ & $0.92 \pm 0.07$ & $1.37 \pm 0.29$ & $5.7 \pm 0.5$ & Linear \\
$\mathrm{j}$ & $1.93 \pm 0.16$ & $0.84 \pm 0.07$ & $0.86 \pm 0.23$ & $5.3 \pm 0.5$ & Planar \\
$\mathrm{k}$ & $2.05 \pm 0.16$ & $0.89 \pm 0.07$ & $0.75 \pm 0.21$ & $5.6 \pm 0.5$ & Planar \\
$\mathrm{l}$ & $2.06 \pm 0.16$ & $0.9 \pm 0.07$ & $0.85 \pm 0.24$ & $5.5 \pm 0.5$ & Planar \\
$\mathrm{m}$ & $2.21 \pm 0.15$ & $0.96 \pm 0.07$ & $1.38 \pm 0.28$ & $6.3 \pm 0.5$ & Linear \\
\hline
\end{tabular}

Regarding seismic hazard analysis conducted in Iran, various predictive relations have been used by a number of investigators in different seismic zones of the country; some considered to be suitable and satisfactory with the logic tree method of seismic hazard analysis (e.g., Sarma and Srbulov (1996), Ramazi (1999), and Ghodrati Amiri et al. (2007)) and some to be incorporated into the Kijko's maximum likelihood estimation of earthquake hazard parameter and Tavakoli's (1996) weighing method of evaluating different seismicity parameters [43-46] [31]. Some of these predictive relations consider the model to be related to Zagros regions and also for Alborz as well as Central Iran in various site conditions to evaluate maximum effective acceleration and velocity for horizontal and vertical directions. Other relations proposed for Iran suggested (e.g., Ramazi (1999)) the evaluation of PGA values based on recorded accelerograms by Iranian seismograph networks [44]. Some investigators consider simultaneously (e.g., Ghodrati Amiri et al. (2007)) relationships covering local situations and those regarding global conditions to reach better compatibility between the relations and the conditions in the region under study [45].

In this study, however, it was decided to use the Abrahamson and Silva (2008) attenuation relationship [47]. These relationships were derived empirically from recorded accelerograms produced by earthquakes in different parts of the world, mostly recorded in Western North America. In place of generic site categories (soil and rock), the site is parameterized by average shear-wave velocity in the top $30 \mathrm{~m} V_{S} 30$ and the depth to engineering rock (depth to $V_{S}=1000$ $\mathrm{m} / \mathrm{s}$ ). Therefore, the relationships quoted above have been accepted as appropriate models for evaluation of the ground motion parameters in this earthquake zonation study [47].

In this study, the Abrahamson and Silva attenuation relation was used, since such a relation has general applicability in most parts of the region in Iran. Further, as mentioned earlier, this relation and all its required parameters and constants are inhibited in crisis 2007 (CRISIS2007) internal library. This facilitates the use of the software, and there is no need to make changes to these parameters or constants by users.

\section{Seismic hazard analysis approach}

In order to reduce the threat and danger of earthquakes to human lives and activities, structures and living or working facilities are to be safely designed for a reasonable and desired level of ground shaking, which is characterized by design motion parameters. A sophisticated approach to evaluating a reasonable ground motion at some acceptable levels of probability of occurrence for earthquake-resistant design (either at ultimate or performance-based levels); hence, a more intelligent and economic design is viewed as Probabilistic Seismic Hazard Analysis (PSHA). This is opposed to DSHA (Deterministic Seismic Hazard Analysis) approach in which the worst-case scenario, or the largest magnitude/closest source-to-site distance amongst various individual scenarios of magnitude and location for each seismic source is adopted.

A general probabilistic approach was originally developed over some decades ago and was extended to many other scientific and engineering disciplines including seismology and geotechnical earthquake engineering. The numerical/analytical approach to PSHA 
was first formalized by Cornell (1968) [48]. To identify, address, and quantitatively assess the uncertainties in the location size and rate of occurrences of earthquake involved (and as part of a PSHA approach), the Senior Seismic Hazard Analysis Committee (SSHAC, 1997) set a goal for all PSHA and represented many important procedural issues. PSHA approach is based on a methodology that enables seismologists, or practicing engineers, to identify, quantify, and, then, rationally combine all these uncertainties to estimate the likelihood of various levels of earthquake-induced ground motions exceeding a given location in an assumed future time period. Peak Ground Acceleration (PGA) was primarily used to quantify ground motion in PSHA (as used to define lateral forces and shear stresses in the equivalent-static-force procedures in building codes and in liquefaction analyses) (e.g., Bagheripour et al., 2012) [49]. In a very brief description, basic components of a PSHA analysis include: (a) seismic source characterization, (b) development of predictive relationships, (c) temporal uncertainty, (d) probability computations, and (e) development of hazard curves.

Based on the preceding paragraphs, it can be inferred that PSHA approach includes assessment of an infinite number of deterministic hazard analyses, with the hazard being integrated into all potential earthquake sources for all scenarios of magnitude and distance. Such an extensive number of analyses present a formidable task which, for the sake of speed of computations, can be incorporated into computer programs. Available software products developed by a variety of researchers or organizations provide essential assistance for conducting hazard analysis.

In the current study, to assess probabilistic seismic hazard, the CRISIS2007 computer program was used to evaluate the distribution of peak ground acceleration and their corresponding probabilities. Some of the main features of this computer program are as follows [50]:

- Earthquake occurrence can be modeled either as a Poisson process or as a Characteristic Earthquake process;

- Sources can be modeled as areas, lines or points;

- CRISIS2007 operates with a dynamic integration procedure which allows fast computation of hazard in extended areas;

- Attenuation models furnished by the user or in built-in CRISIS2007 provide great flexibility for the computations;

- A user-friendly graphical interface facilitates data input;

- Values calculated for earthquake hazard are displayed as iso-acceleration contours to be exceeded during typical economic lifetime of structures.
Other investigators have used another computer program such as SEISRISK III (e.g. Ghodrati Amiri et al., 2010) for hazard analysis [27]. From engineering point of view, selected ground motions (or ground motion parameters) are further used for seismic analyses using analytical procedures, or for being introduced into a variety of engineering softwares as inputs. Further applications of results derived from a PSHA approach include development of the uniform hazard spectra and design spectra as well as the development of acceleration time histories. The latter can be further applied to the important geotechnical engineering problems such as site response analysis using a variety of analytical and numerical techniques to evaluate amplification of seismic waves in soil layers [49,51-57].

\subsection{Results and discussions}

In this section, seismic hazard maps in terms of Peak Ground Acceleration (PGA (g)) for Kerman city and its vicinities for 50-, 75-, and 475-year return periods are presented.

Figure 7(a) presents plan contour of the predicted PGA for Kerman city and its vicinities developed for a 50-year return period. A better representation of the PGA distribution in the area can be shown in Figure 7 (b) by a 3D scheme of the variations in PGA. It can be seen that the level of predicted PGA varies in the area such that, in the area's west, PGA level is low and limited to $0.05 \mathrm{~g}$. However, an increasing trend is observed while moving towards east of the region. An extreme level of $0.17 \mathrm{~g}$ is seen in S-E of the area.

Figure 8(a) also depicts variations of PGA in Kerman region developed for a 75-year return period. The level of PHA in the west reaches a minimum value of $0.06 \mathrm{~g}$, while eastern parts of the area are struck by a maximum ground acceleration of up to $0.23 \mathrm{~g}$ in such a return period. In comparison to Figure 7, it can be inferred that a similar trend of increasing PGA values from west to east governs the map of the area. However, an increase in return period also causes an increase in PGA in all areas of the map. Similar to Figure 7(b), Figure 8(b) presents a 3D view of variations in PGA values in the region.

Seismic hazard map of Kerman region developed for a 475-year return period associated with plan contours of PHA is also shown in Figure 9(a). It can be seen that the lowest values for PGA (0.14 g) are observed in the west and constantly increase by moving towards the east. An extreme value of $0.6 \mathrm{~g}$ is observed for PHA in the east of the area and, especially, in $\mathrm{S}-\mathrm{E}$ of the region. This again shows the potential of the S-E part of the region (the Kuhbanan fault zone and the Shahdaad fault zone) to be hit by strong ground motions in the future, hence the necessity of reconsidering the existing seismic design procedures, 


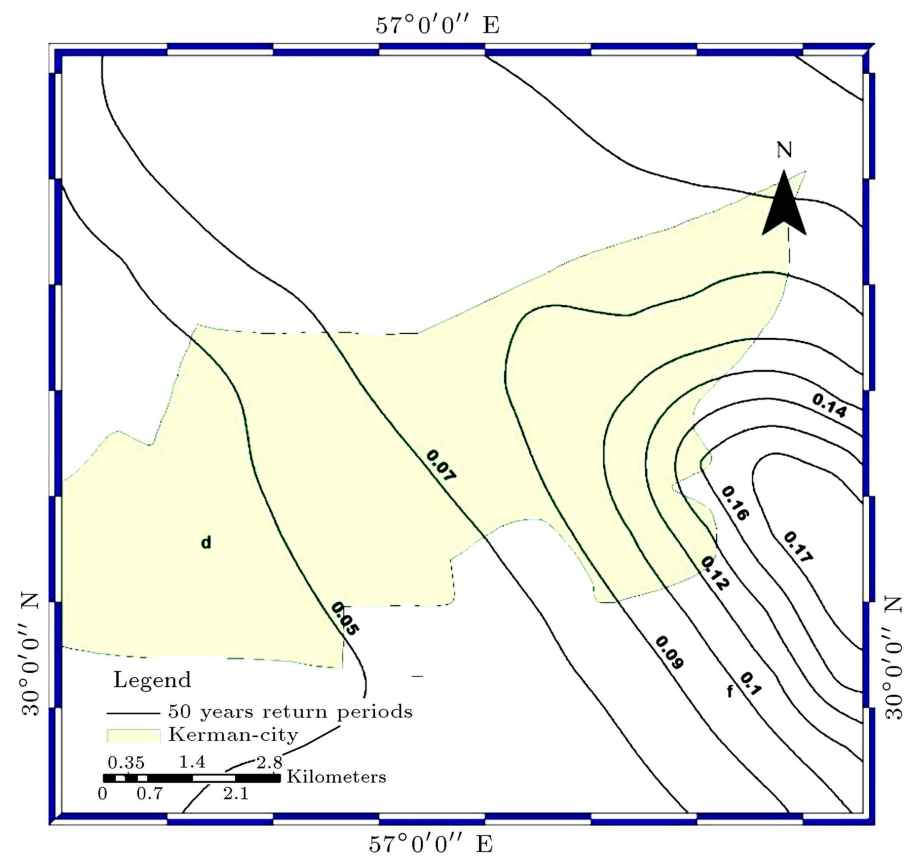

(a)

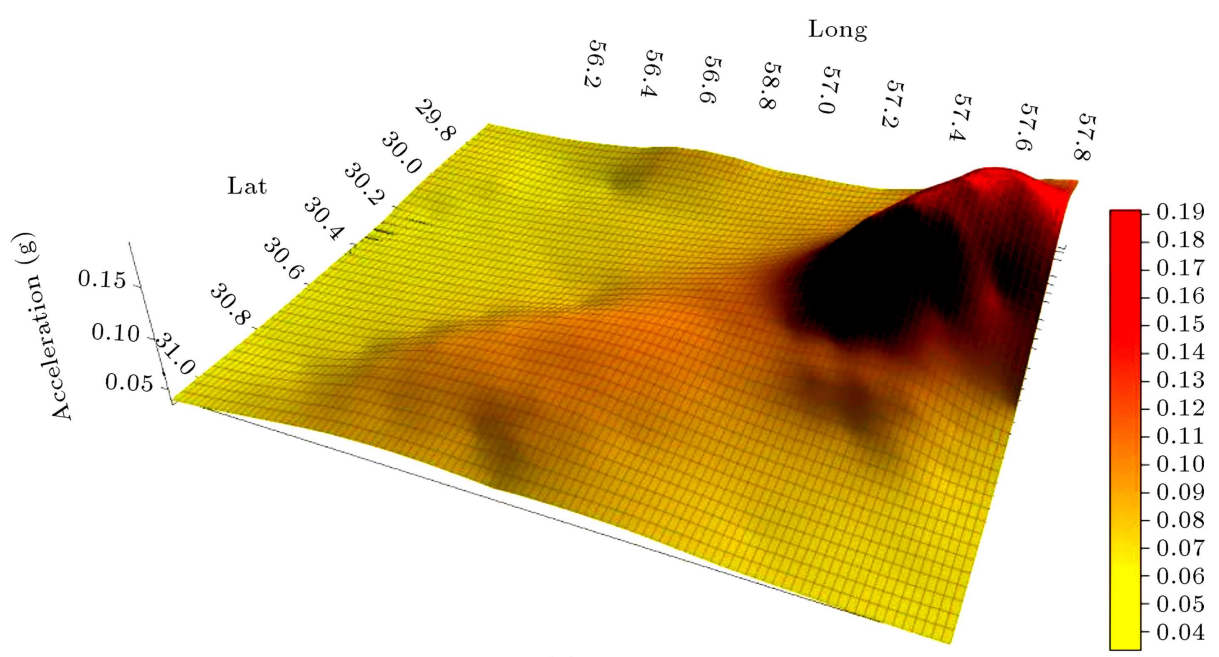

(b)

Figure 7. Seismic hazard map in terms of PGA (g) in Kerman and its vicinity for a 50-year return period: (a) Plan map for PGA variation in bordered Kerman region and (b) three-dimensional presentation of PGA variation in the region.

particularly for important structures and even strategic infrastructure. Similar to Figures $7(\mathrm{~b})$ and $8(\mathrm{~b})$, a better visual perception of PGA variations for a 475year return period is schematically shown by $3 \mathrm{D}$ surface map in Figure 9(b). The latter value adopted for return period (475-years) coincides with the Design Basis Earthquake (DBE) defined by the Iranian building code for which design-based accelerations are developed. In this study, therefore, a comparison is presented in Section 7.2 with such a building code.

A general conclusion can be made based on the results presented in Figures 7 to 9, such that the S$\mathrm{E}$ of the area can be highly prone to strong motions; hence, retrofitting the existing buildings and upgrading seismic design procedures for future structures are vitally required.

Figures 10 to 12 show the scatter of earthquakes' magnitude to distance observed in the site of study developed respectively for 50-, 75-, and 475-year return periods. It can be seen that most of hazards (maximum magnitudes) are expected to be originated from seismic sources located at a distance of 20 to $50 \mathrm{~km}$ from the site. Figure 11, for example, shows that the expected maximum magnitudes are of seismic sources in the range of $20-50 \mathrm{~km}$ from the site of the study when a 75 -year return period is considered.

Figure 12 similarly depicts the scatter of magnitudes based on the distance from the site and for a 


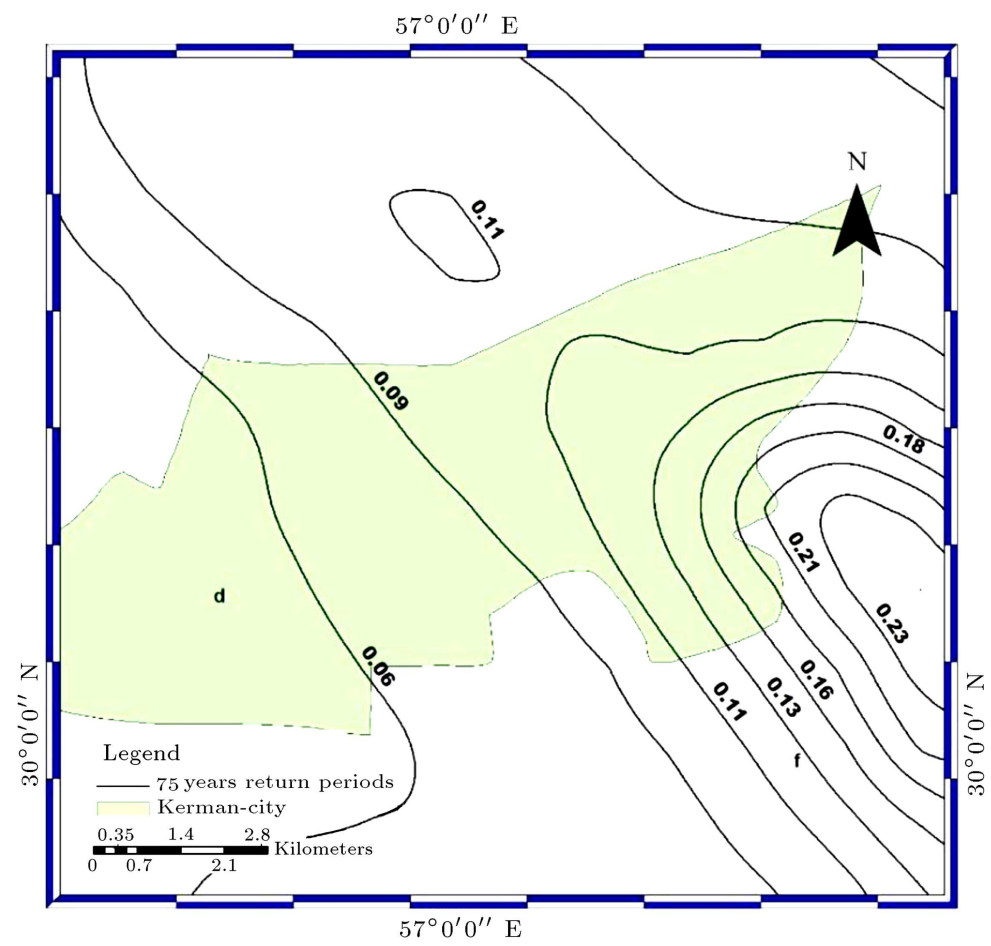

(a)

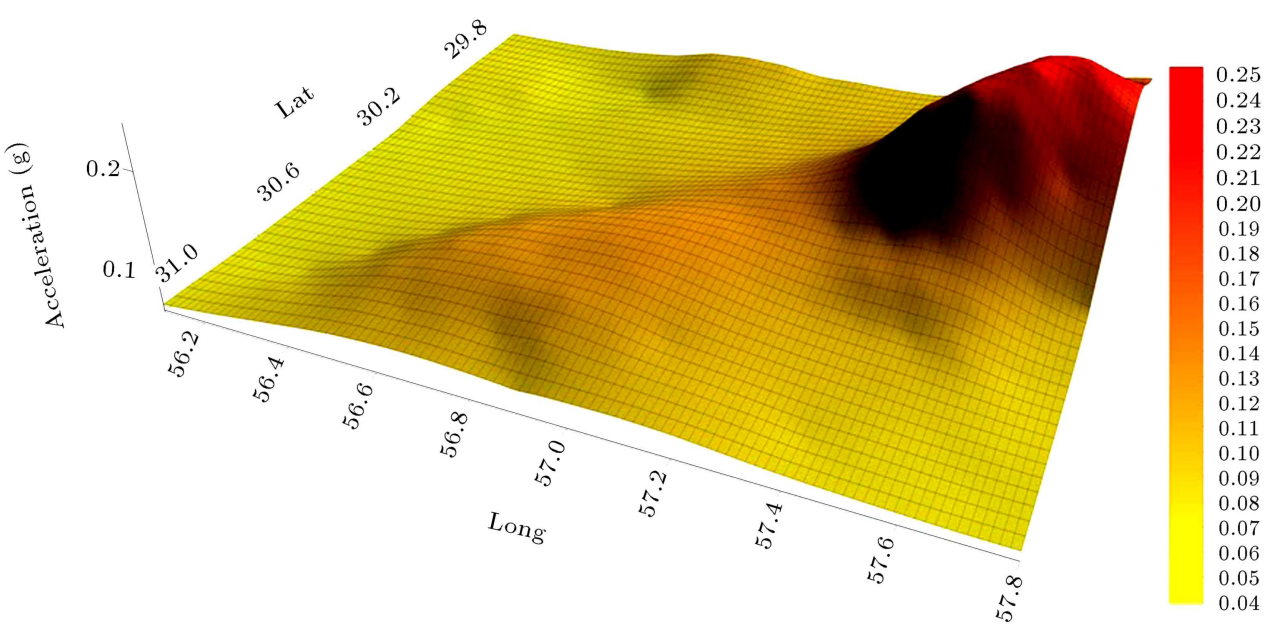

(b)

Figure 8. Seismic hazard map in terms of PGA (g) in Kerman and its vicinity for a 75-year return period: (a) Plan map for PGA variation in bordered Kerman region and (b) three-dimensional presentation of PGA variation in the region.

475-year return period. Similarly, it can be seen that maximum magnitude is developed by seismic sources distant at $20 \mathrm{~km}$ from area.

Generally, much of the hazard comes from earthquakes of $M_{w}=5$ distanced at $20 \mathrm{~km}$ of the site.

\subsection{Comparison with building codes}

The Iranian Code of Practice for Seismic-Resistant Design of Building (Standard No. 2800 Version 4) [12] defines that Design Basis Earthquake (DBE) is a strong earthquake with $10 \%$ probability of exceedance in 50 years (approximate lifetime of structures). This is equivalent to the return period of 475 years since Poisson's probability theory governs. On the other hand, an earthquake with $99.5 \%$ probability of exceedance in 50 years is regarded as performance-based design (PBE) earthquake by the Iranian code of practice.

According to the current hazard map of Iran used in the Iranian code of practice for DBE, areas located in hazard levels I, II, III, IV are characterized with $0.35 \mathrm{~g}, 0.3 \mathrm{~g}, 0.25 \mathrm{~g}$, and $0.2 \mathrm{~g}$, respectively. Based on this map, Kerman region falls in areas III to IV with varying hazard levels of $0.3 \mathrm{~g}$ to $0.35 \mathrm{~g}$.

However, based on the hazard map developed in 


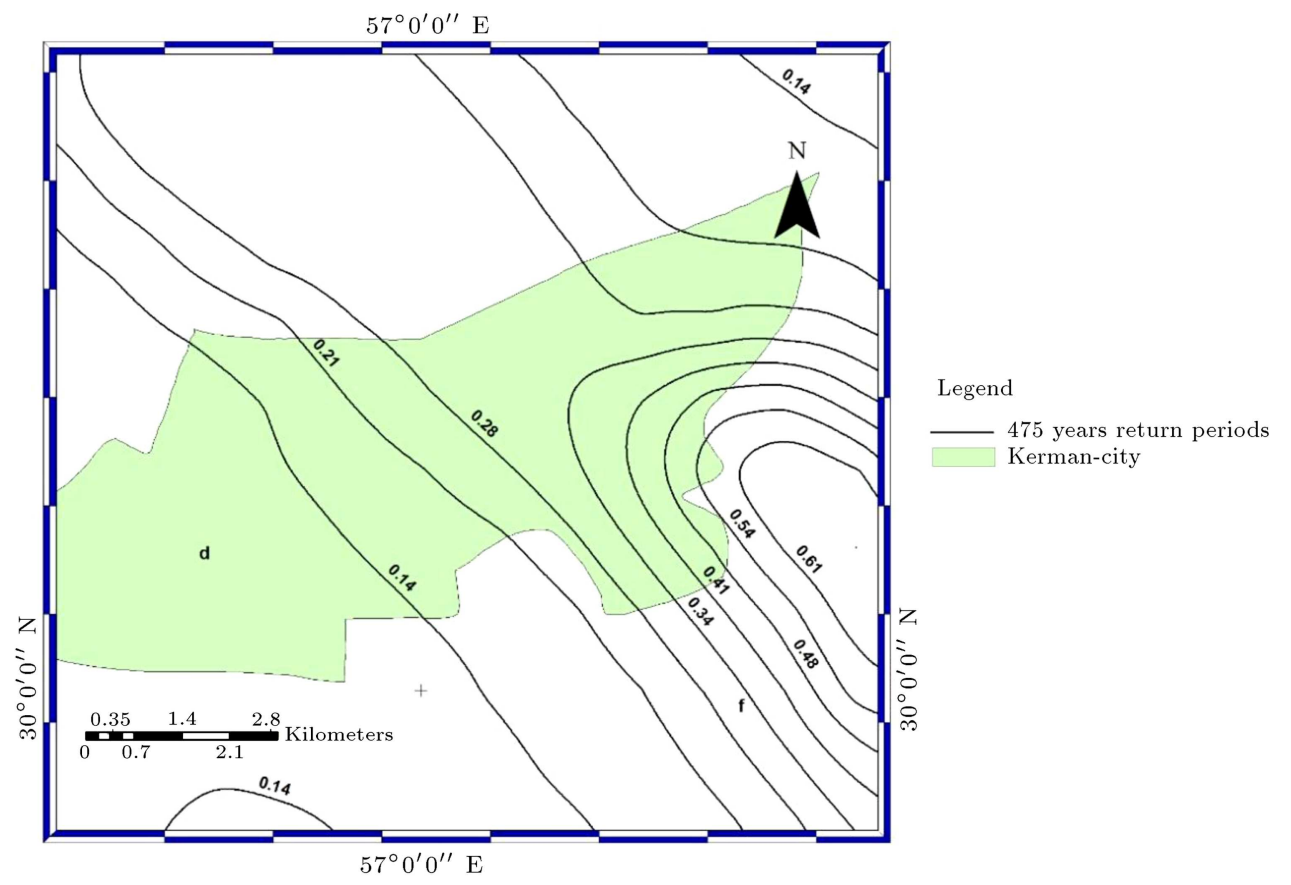

(a)

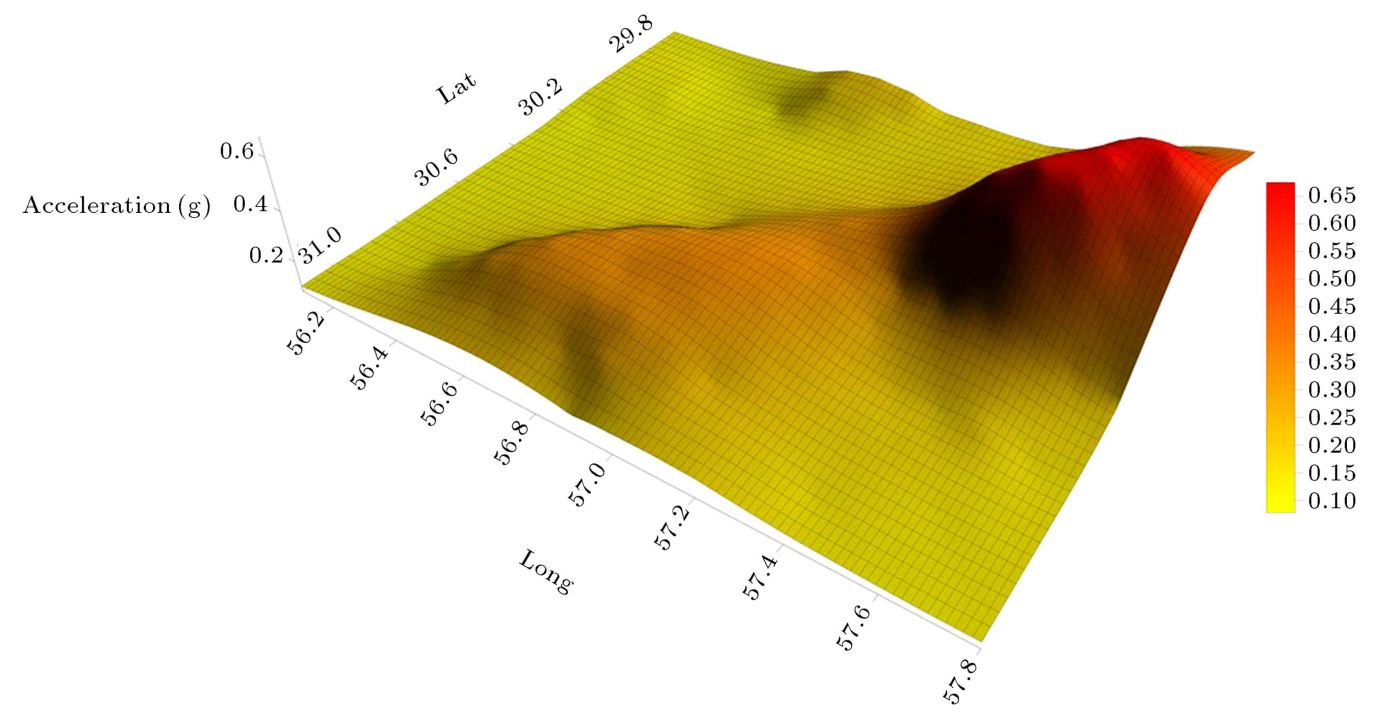

(b)

Figure 9. Seismic hazard map in terms of PGA (g) in Kerman and its vicinity for 475-year return period: (a) Plan map for PGA variation in bordered Kerman region and (b) three-dimensional presentation of PGA variation in the region.

the current study, the ground acceleration for $10 \%$ probability of exceedance in 50 years (475-year return period) varies from a minimum value of $0.14 \mathrm{~g}$ to the west of the area and exceeds $0.6 \mathrm{~g}$, especially in S-E of the region which appears higher than the suggested value by the Iranian Code of Practice.

\section{Conclusions}

Iran is located in one of the world's most seismically active zones situated over the Alp-Himalayan seismic belt, and Kerman region in S-E of Iran is the most susceptible area in the country. A review of the hazard level was made in this paper for the Kerman region through seismic hazard analysis. PSHA approach was used to evaluate the distribution of PGA and its corresponding probabilities for Kerman region.

Historical and instrumental earthquake records cover certain information on seismotectonic system, and coordinate information related to regional faults was used as a database. Kijko method was used to evaluate seismicity parameters of regional seismic sources, since it accounts for incomplete or inaccurate seismic data. CRISIS2007 software was also used 


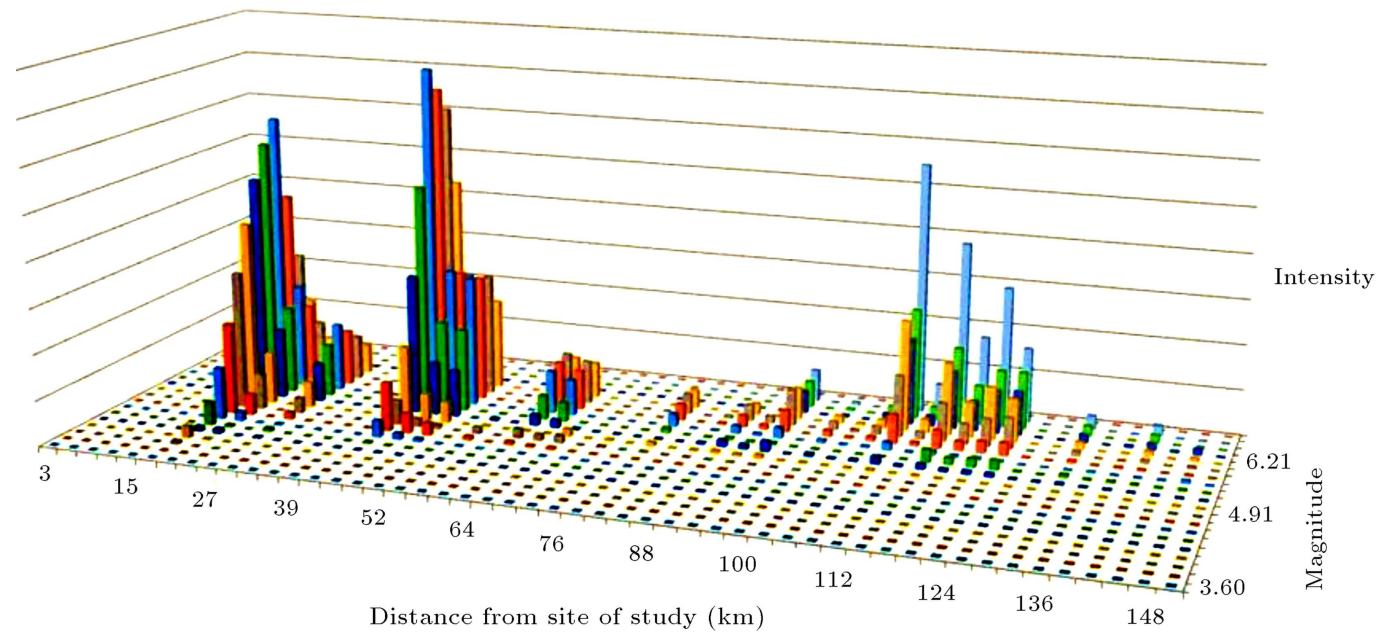

Figure 10. Scatter of earthquakes by magnitude to distance from the site of study for a 50 -year return period.

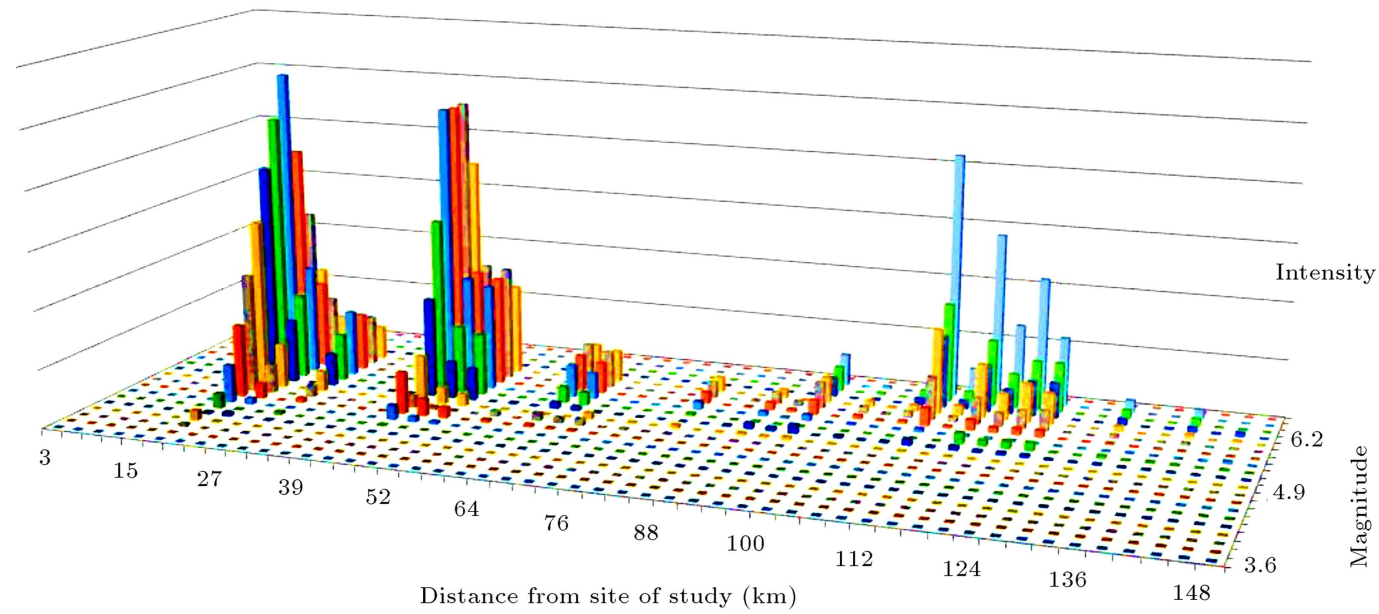

Figure 11. Scatter of earthquakes by magnitude to distance from the site of study for a 75-year return period.

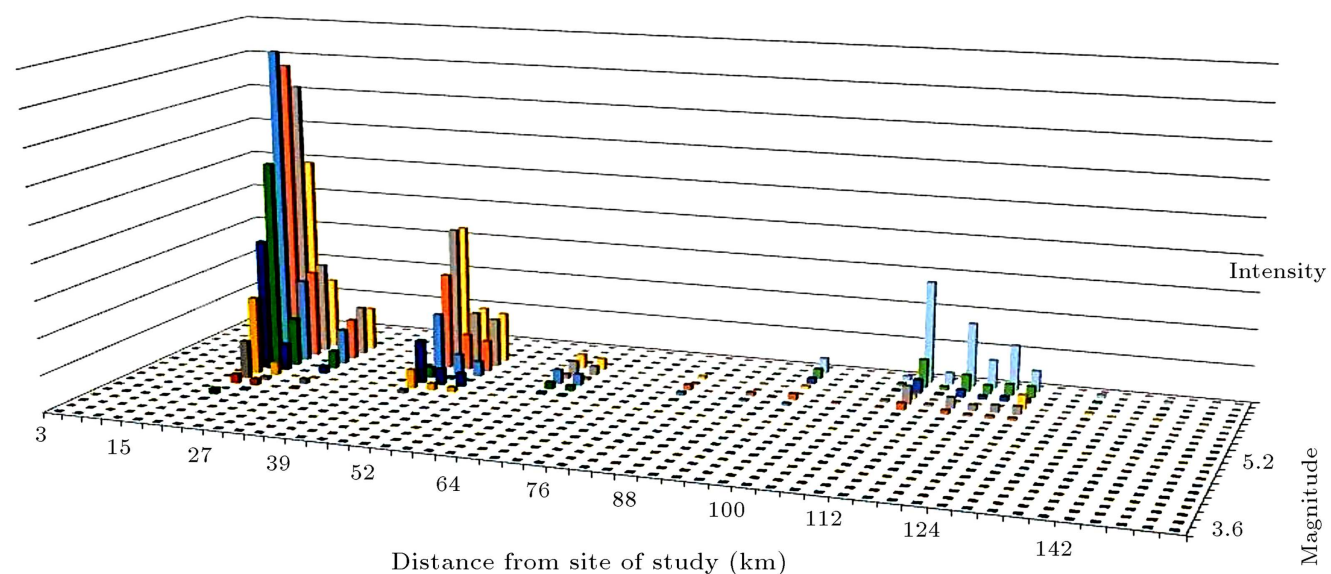

Figure 12. Scatter of earthquakes by magnitude to distance from the site of study for a 475-year return period.

next to carry out seismic hazard analysis for the region and to develop the maps of iso-acceleration contours for various return periods. Some return periods were adopted, for which distribution of PGA values was evaluated. A comparison of results was partially made with those given by the Iranian Code of practice for Seismic-Resistant Design of Buildings.

The important results obtained from this study are outlined as follows: 
1. The highest acceleration contours encompass the east of Kerman city, the Kuhbanan fault zone, and the Shahdaad fault zone. The maximum mean acceleration in the vicinity of these tectonic elements was predicted to be around $0.17 \mathrm{~g}$ for a return period of 50 years, $0.23 \mathrm{~g}$ for a return period of 75 years, and $0.61 \mathrm{~g}$ for a return period of 475 years. The latter return period corresponds to $10 \%$ probability of exceedance in 50 years, denoted by the Iranian Code of Practice for Seismic-Resistant Design of Buildings as Design Basis Earthquake (DBE). Based on the hazard map developed by this building code, a value of $0.3 \mathrm{~g}$ to $0.35 \mathrm{~g}$ for Kerman region was suggested when DBE approach was used. Therefore, PGA values obtained from this study, therefore, appeared to be more than those suggested by building codes;

2. The smallest accelerations were expected in the Laaleh zaar fault zone, and Rafsanjaan fault zone's maximum acceleration values for both of these regions were $0.06 \mathrm{~g}$ and $0.14 \mathrm{~g}$ for return periods of 75 and 475 years, respectively;

3. Results showed the potential of the S-E part of the region to be hit by strong ground motions in the future and, hence, the necessity of reconsidering the existing seismic design procedures, particularly for important structures and even strategic infrastructure;

4. The maps were intended for the assessment of the seismic hazard for engineering structures. Moreover, they may also be used for other purposes such as the preparation of seismic risk maps, the estimation of earthquake insurance premiums, and the preliminary site evaluation of critical facilities.

\section{References}

1. Tatar, M., Hatzfeld, D., Moradi, A., and Paul, A. "The 2003 December 26 Bam earthquake (Iran), Mw 6.6, aftershock sequence", Geophysical Journal International, 163(1), pp. 90-105 (2005).

2. Jackson, J., Bouchon, M., Fielding, E., Funning, G., Ghorashi, M., Hatzfeld, D., Nazari, H., Parsons, B., Priestley, K., and Talebian, M. "Seismotectonic, rupture process, and earthquake-hazard aspects of the 2003 December 26 Bam, Iran, earthquake", Geophysical Journal International, 166(3), pp. 1270-1292 (2006).

3. Nalbant, S.S., Steacy, S., and McCloskey, J. "Stress transfer relations among the earthquakes that occurred in Kerman province, southern Iran since 1981", Geophysical Journal International, 167(1), pp. 309-318 (2006).

4. Berberian, M., Jackson, J., Ghorashi, M., and Kadjar, M. "Field and teleseismic observations of the 1981
Golbaf-Sirch earthquakes in SE Iran", Geophysical Journal International, 77(3), pp. 809-838 (1984).

5. Berberian, M., Jackson, J., Fielding, E., Parsons, B., Priestley, K., Qorashi, M., Talebian, M., Walker, R., Wright, T.J., and Baker, C. "The 1998 March 14 Fandoqa earthquake ( $\mathrm{Mw}$ 6.6) in Kerman province, southeast Iran: re-rupture of the 1981 Sirch earthquake fault, triggering of slip on adjacent thrusts and the active tectonics of the Gowk fault zone", Geophysical Journal International, 146(2), pp. 371-398 (2001).

6. Talebian, M., Biggs, J., Bolourchi, M., Copley, A., Ghassemi, A., Ghorashi, M., Hollingsworth, J., Jackson, J., Nissen, E., and Oveisi, B. "The Dahuiyeh (Zarand) earthquake of 2005 February 22 in central Iran: reactivation of an intramountain reverse fault", Geophysical Journal International, 164(1), pp. 137148 (2006).

7. Rouhollahi, R., Ghayamghamian, M., Yaminifard, F., Suhadolc, P., and Tatar, M. "Source process and slip model of 2005 Dahuiyeh-Zarand earthquake (Iran) using inversion of near-field strong motion data", Geophysical Journal International, 189(1), pp. 669680 (2012).

8. Rahnama-Rad, J., Firuzan, M., and Baraeenejhad, M. "Soil collapsibility of Kerman city", 1st Int. Applied Geological Congress, Department of Geology, Islamic Azad University, Mashad, Iran, pp. 1-6 (2010).

9. Kijko, A. and Sellevoll, M.A. "Estimation of earthquake hazard parameters from incomplete data files. Part I. Utilization of extreme and complete catalogs with different threshold magnitudes", Bulletin of the Seismological Society of America, 79(3), pp. 645-654 (1989).

10. Kijko, A. and Sellevoll, M.A. "Estimation of earthquake hazard parameters from incomplete data files. Part II. Incorporation of magnitude heterogeneity", Bulletin of the Seismological Society of America, 82(1), pp. 120-134 (1992).

11. Kijko, A. "Statistical estimation of maximum regional earthquake magnitude Mmax", Workshop of Seismicity Modeling in Seismic Hazard Mapping, Poljce, Slovenia, Geological Survey, (2000).

12. "Iranian Code of Practice for Seismic Resistant Design of Buildings", Standard No. 2800, Version 4, Road, Housing \& Urban Development Research Center (pub.), BHRC-PNS-253 (In Persian) (2014).

13. Ambraseys, N. and Melville, C. A History of Persian Earthquakes, Cambridge Univ., Press, New York, (1982).

14. Berberian, M. "Natural Hazards and the first earthquake catalogue of Iran", Historical Hazards in Iran Prior to 1900, International Institute of Earthquake Engineering and Seismology, Tehran, 1, p. 603 (1994).

15. Tavakoli, B. and Ghafory-Ashtiany, M. "Seismic hazard assessment of Iran", Annals of Geophysics, 42(6), pp. 1013-1021 (1999). 
16. Niazi, M. and Basford, J.R. "Seismicity of Iranian plateau and Hindu Kush region", Bulletin of the Seismological Society of America, 58(1), pp. 417-426 (1968).

17. Nowroozi, A.A. "Seismo-tectonics of the Persian plateau, eastern Turkey, Caucasus, and Hindu-Kush regions", Bulletin of the Seismological Society of America, 61(2), pp. 317-341 (1971).

18. Nowroozi, A.A. "Seismotectonic provinces of Iran", Bulletin of the Seismological Society of America, 66(4), pp. 1249-1276 (1976).

19. Banisadr, M. "The seismicity of Iran: 1900-1969", Technical Research and Standard Bureau, Plan Organization, (1971).

20. Ambraseys, N. and Moinfar, A. "The seismicity of Iran. The Silakhor, Lurestan, earthquake of 23rd January, 1909", Annali di geofisica, 26(4), pp. 659-678 (1973).

21. Berberian, M., The Seismicity of Iran Preliminary Map of Epicentres and Focal Depth 1:2 500 000, Geological survey of Iran, Seismotectonic Group (1973).

22. Tchalenko, J. "Seismicity and structure of the North Tehran fault", Tectonophys, 29, pp. 411-420 (1975).

23. Nabavi, S. "Historical earthquakes in Iran, 300BC1900 AD", Journal of Earth and Space Physics, 7(1), pp. 70-117 (1978).

24. Berberian, M. "Discussion of the paper AA Nowroozi, 1976, seismotectonic provinces of Iran", Bulletin of the Seismological Society of America, 69(1), pp. 293-297 (1979).

25. Ambraseys, N. and Melville, C., A History of Persian Earthquakes, Cambridge University Press (2005).

26. Mousavi-Bafrouei, S.H., Mirzaei, N., and Shabani, E. "A declustered earthquake catalog for the Iranian Plateau", Annals of Geophysics, 57(6), pp. 1-25 (2015).

27. Ghodrati Amiri, G.H., Kazemiashtiani, V., and Razavian, S. "Seismic hazard analysis and obtaining peak ground acceleration for Arak region, Iran", Asian J. Civil Eng. (Building Hous), 11, pp. 183-206 (2010).

28. Stocklin, J. "Structural history and tectonics of Iran: A review", AAPG Bulletin, 52(7) pp. 1229-1258 (1968).

29. Takin, M. "Iranian geology and continental drift in the Middle East", Nature, 235, pp. 147-150 (1972).

30. Berberian, M. "Contribution to the seismotectonics of Iran (part II-III)", In Commemoration of the 50th Anniversary of the Pahlavi Dynasty, Ministry of Industry and Mines, Geological Survey of Iran, Tectonic and Seismotectonic Section (1976).

31. Tavakoli, B., Major Seismotectonic Provinces of Iran, International Institute of Earthquake Engineering and Seismology, Internal Document (1996).

32. Hanks, T.C. and Kanamori, H. "A moment magnitude scale", Journal of Geophysical Research, 84, pp. 23452350 (1979).
33. Aki, K. "Earthquake mechanism", Tectonophysics, 13(1-4), pp. 423-446 (1972).

34. Karimiparidari, S., Zaré, M., Memarian, H., and Kijko, A. "Iranian earthquakes, a uniform catalog with moment magnitudes", Journal of Seismology, 17(3), pp. 897-911 (2013).

35. Ghodrati Amiri, G., Amrei, S.R., editors. "Seismic hazard assessment of Gilan province including Manjil in Iran", Proc 14th World Conf Earthquake Eng, Beijing, China (2008).

36. Ghodrati Amiri, G., Andisheh, K., Razavian, A., and Seyed, A. "Probabilistic seismic hazard assessment of Sanandaj, Iran", Structural Engineering and Mechanics (Techno-Press), 32(4), pp. 563-581 (2009).

37. Kijko, A. and Graham, G. "Parametric-historic procedure for probabilistic seismic hazard analysis, Part II: Assessment of seismic hazard at specified site", Pure and Applied Geophysics, 154, pp. 1-22 (1999).

38. Kramer, S., Geotechnical Earthquake Engineering, Prentice-Hall international series in Civil Engineering and Engineering Mechanics, Prentice Hall, USA, (1996).

39. Gutenberg, B., and Richter, C.F. "Earthquake magnitude, intensity, energy, and acceleration (second paper)", Bulletin of the Seismological Society of America, 46(2), pp. 105-145 (1956).

40. Wesnousky, S., Scholz, C., Shimazaki, K., and Matsuda, T. "Integration of geological and seismological data for the analysis of seismic hazard: A case study of Japan", Bulletin of the Seismological Society of America, 74(2), pp. 687-708 (1984).

41. Youngs, R.R. and Coppersmith, K.J. "Implications of fault slip rates and earthquake recurrence models to probabilistic seismic hazard estimates", Bulletin of the Seismological Society of America, 75(4), pp. 939-964 (1985).

42. Sharma, M.L. "Attenuation relationship for estimation of peak ground horizontal acceleration using data from strong-motion arrays in India", Bulletin of the Seismological Society of America, 88(4), pp. 1063-1069 (1998).

43. Sarma, S. and Srbulov, M. "A simplified method for prediction of kinematic horizontal acceleration of a rigid foundation", Earthquake Engineering and Structural Dynamics, 25, pp. 815-836 (1996).

44. Ramazi, H., Editor. "Attenuation laws of Iranian earthquakes", Proceedings of the 3rd International Conference on Seismology and Earthquake Engineering, Tehran, Iran (1999).

45. Ghodrati Amiri, G.h., Mahdavian, A., and Dana, F.M. "Attenuation relationships for Iran", Journal of Earthquake Engineering, 11(4), pp. 469-492 (2007).

46. Kijko, A. "Estimation of the maximum earthquake magnitude, m max", Pure and Applied Geophysics, 161(8), pp. 1655-1681 (2004). 
47. Abrahamson, N. and Silva, W. "Summary of the Abrahamson \& Silva NGA ground-motion relations", Earthquake Spectra, 24(1), pp. 67-97 (2008).

48. Cornell, C.A. "Engineering seismic risk analysis", Bulletin of the Seismological Society of America, 58(5), pp. 1583-1606 (1968).

49. Bagheripour, M.H., Shooshpasha, I., and Afzalirad, M. "A genetic algorithm approach for assessing soil liquefaction potential based on reliability method", Journal of Earth System Science, 121(1), pp. 45-62 (2012).

50. Ordaz, M., Aguilar, A., and Arboleda, J. CRISIS200\%: Program for Computing Seismic Hazard, National Autonomous University of Mexico, Mexico (2007).

51. Ouria, A., Desai, C.S., and Toufigh, V. "Disturbed state concept-based solution for consolidation of plastic clays under cyclic loading", International Journal of Geomechanics, ASCE., 15(1), 04014039 (2013).

52. Toufigh, V., Desai, C.S., Saadatmanesh, H., Toufigh, V., Ahmari, S., and Kabiri, E. "Constitutive modeling and testing of interface between backfill soil and fiberreinforced polymer", International Journal of Geomechanics, ASCE, 14(3), 04014009 (2013).

53. Kianfar, E. and Toufigh, V. "Reliability analysis of rammed earth structures", Construction and Building Materials, 127, pp. 884-895 (2016).

54. Bazrafshan Moghaddam, A., and Bagheripour, M.H. "Ground response analysis using non-recursive matrix implementation of hybrid frequency-time domain (HFTD) approach", Scientia Iranica, 18(6), pp. 11881197 (2011).

55. Bazrafshan Moghaddam, A. and Bagheripour, M.H. "Earthquake time-frequency analysis using a new compatible wavelet function family", Earthquakes and Structures (Techno-Press), 3(6), pp. 839-852 (2012).

56. Saffarian, M.A. and Bagheripour, M.H. "Seismic response analysis of layered soils considering effect of surcharge mass using HFTD approach. Part I: Basic formulation and linear HFTD", Geomechanics and Engineering (Techno-Press), 6(6), pp. 517-530 (2014).

57. Saffarian, M.A. and Bagheripour, M.H. "Seismic response analysis of layered soils considering effect of surcharge mass using HFTD approach. Part II: Nonlinear HFTD and numerical examples", Geomechanics and Engineering (Techno-Press), 6(6), pp. 531-544 (2014).

\section{Biographies}

Maalek Saafizaadeh graduated from Payam Nour University in 2008 with a BSc degree in Physics. From 2011, he continued higher educations at Graduate University of Advanced Technology in Kerman, Iran. He graduated in 2013 and received his MSc degree in Geophysics. Since then, he has been active in various geophysical and subsurface exploration projects in S-E of Iran and has carried out several respective seismic researches in the area.

Mohammad Hossein Bagheripour received his BS degree in Civil Engineering from Shahid Bahonar University of Kerman in 1988. He worked as a Consulting Engineer in civil projects in south-east Iran before moving to Australia to continue his postgraduate studies. In 1993, he received his MEng degree from the University of Sydney and was also awarded a PhD degree in Geotechnical Engineering in 1997 for his continuing research work on jointed rock mechanics. Immediately after graduation, he returned to Kerman, Iran, where he is currently a Faculty Member and Professor at the Civil Engineering Department of Shahid Bahonar University of Kerman. His research interests include soil and rock mechanics in general and earthquake geotechnical engineering in particular. He has published several papers in various journals and presented many others at national and international conferences. 